\title{
Interpretation of Hakka furniture from visual semiotics
}

\author{
Juan Xie ${ }^{1, *}$, Wen Zhang ${ }^{2}$ \\ ${ }^{1}$ Gannan normal University, Fine art college, 341412 Ganzhou City Jiangxi Province, China \\ ${ }^{2}$ Gannan normal University, Fine art college, 341412 Ganzhou City Jiangxi Province, China
}

\begin{abstract}
Furniture is kind of a symbol or a system composed of symbols, and the profound cultural meaning of what furniture contains can be expressed through the use of furniture symbols, including the regional attributes and cultural connotations of furniture. Hakka furniture is a member of the traditional furniture, with its distinctive style and extremely high artistic and aesthetic value. In this paper, from the perspective of semiotics, using Pierce's classification of semiotics, combined with the characteristics of Hakka furniture, Hakka furniture symbols to interpret its hidden behind the social significance and aesthetic value.
\end{abstract}

\section{Background of Hakka furniture}

"Hakka" is a branch of the Han nationality. Hakka folk art was developed on the basis of the mainstream culture of the Han nationality. about 1000 years ago, the people in the cultural core area fled to the mountainous areas in the South in order to avoid the war and settled down. in the course of settling in Fujian, Guangdong and Jiangxi, they absorbed and integrated the local cultural characteristics, and gradually formed and developed. It became a new cultural motif of the mixed North and South and the harmony between the old and the new after the variation of the Han culture[1].

Hakka traditional furniture, as a material carrier of the cultural connotation and aesthetic characteristics of Hakka people, has a wide variety of categories, different forms, and profound meanings. Nowadays, the traditional Hakka family retained a lot furniture from the Ming and Qing dynasty. The sources of these furniture are mainly from two aspects: Some of them were imported by officials or businessmen from other places , and others were made by the traditional Hakka craftsmen using local raw materials in the area where the Hakka people live.

Hakka furniture originated from Ming and Qing style furniture in Central China, and integrated into the southern Jiangxi Hakka special geographical environment, customs and cultural.The appearance of the furniture is simple, and the carvings are mostly auspicious themes. .These ornament themes reflect the Chinese people emphasis on culture and education, and pay attention to personal cultivation[2].Hakka traditional furniture is rich in cultural connotation and has a long history. All these cultural connotations are fully represented in Hakka furniture and interior decoration. The carvings and drawings on the furniture are full of meanings, reflecting not only the exquisite craftsmanship of the Hakka people, but also their fine traditions and life values, as well as their willingness to refine their qualities and pursue a better life. Hakka's initial furniture were mostly practical, and by the Ming dynasty there was a high level of woodworking and lacquering, which enabled them to manufacture higher-grade wooden furniture and export wood products such as tables and chairs, screens, teapots, and cabinets.

\section{Symbolic analysis of Hakka furniture}

The symbolic representation of the modeling form in Hakka furniture is mainly decorative symbol, functional indicator symbol and layout symbol, which constitute the Ming-style Chair Furniture with rich modeling after a certain combination and arrangement, and then convey a wide range of implication. It should be noted that the meaning conveyed by each symbol needs to be considered in furniture as a entirety .

\subsection{Decorative symbols for furniture}

Some of the Hakka furniture has carvings with exquisite decorative patterns, and the decorative patterns of these carvings can not only beautify the furniture, but also become a symbolic vehicle for people to express their spiritual world. The ornament themes of folk art is complex and varied. It originates from the extensive and profound Chinese traditional culture, and is a proof of the evolution of Hakka's unique folk culture, customs and religious history[3].

In accordance with Pierce's theory of symbol classification, the system of symbols for Hakka furniture decoration can be divided into pictorial symbols, indicative symbols and symbolic symbols. The symbol of image layer shows that its object indexing symbol and its reference object have some cause and effect or spacetime connection through realism or imitation. These

\footnotetext{
* Corresponding author: $375034291 @$ qq.com
} 
symbols include animal symbols, plant symbols, human symbols, text symbols, object symbols and other visual recognition systems; Indicator symbols Indicator symbols refer to symbols in which there is some kind of logical relationship between symbol form and meaning [4]. Include totem symbol, religion symbol, sacrifice symbol, communication symbol, identity symbol, life symbol and other behavior recognition system; conceptual level symbolic symbol refers to that symbol that has no specific similarity or logical relationship between the form of symbol and the content of meaning, but relies on the convention to form a connection. Include life symbol, reproduction symbol, blessing symbol, aesthetic symbol, philosophy symbol and so on. Its can be easily found from the furniture decoration that plants, animals, utensils, and other patterns are used, and its meaning is extended by its allegory, such as pine tree symbolizing longevity, grape symbolizing have many children, carp symbolizing wealth, and Kilin symbolizing auspiciousness [5].

In addition to expressing feelings by means of implied meaning, in the long-term process of schema evolution, some things also agreed to be abstracted into auspicious symbols, such as the "dark Eight Immortals". For example, in order to express the abstract idea of "having children and succeeding children,"Furniture Decoration is often replaced by things with similar morphological characteristics in life, such as fish and Lotus (Table 1).

Table1.Ornament themes of hakka furniture

\begin{tabular}{|c|c|c|}
\hline $\begin{array}{c}\text { Ornament } \\
\text { themes }\end{array}$ & Representative type & Meaning \\
\hline $\begin{array}{c}\text { Auspiciou } \\
\text { s animals }\end{array}$ & $\begin{array}{c}\text { Dragon,Phoenix,Bir } \\
\text { d,Lion,Kilin,Crane, } \\
\text { fish,deer,cattle,mag } \\
\text { pie,turtle, etc. }\end{array}$ & $\begin{array}{l}\text { Animal symbols are used } \\
\text { to express health and } \\
\text { vitality, birds and insects } \\
\text { express love and } \\
\text { reproduction }\end{array}$ \\
\hline $\begin{array}{c}\text { Flowers } \\
\text { and plants }\end{array}$ & $\begin{array}{l}\text { Peony, lotus, plum, } \\
\text { orchid,Begonia } \\
\text { flowers, cypresses, } \\
\text { chrysanthemums, } \\
\text { bamboo,Peach } \\
\text { blossom, hibiscus, } \\
\text { hydrangea,vine } \\
\text { grass,etc. }\end{array}$ & $\begin{array}{l}\text { Flower auspicious } \\
\text { symbols are used to } \\
\text { express beautiful things, } \\
\text { generally used to express } \\
\text { love and marriage, and } \\
\text { tree and plant symbols } \\
\text { are used to express the } \\
\text { tenacity of life or firm } \\
\text { spirit. }\end{array}$ \\
\hline Deity & $\begin{array}{l}\text { Taoist fairy, fairy, } \\
\text { longevity } \\
\text { Immortals , } \\
\text { Eight Immortals, } \\
\text { Niulan and } \\
\text { Zhinv,etc. }\end{array}$ & $\begin{array}{l}\text { The deity symbol mainly } \\
\text { comes from religion, } \\
\text { especially Taoism, } \\
\text { which mainly means to } \\
\text { stay away from evil and } \\
\text { longevity }\end{array}$ \\
\hline $\begin{array}{l}\text { Chinese } \\
\text { character } \\
\text { symbol }\end{array}$ & $\begin{array}{l}\text { Happiness 喜,Good } \\
\text { fortune 福,longevity } \\
\text { 寿 }\end{array}$ & $\begin{array}{l}\text { The Chinese characters } \\
\text { of 福禄寿喜 intuitively } \\
\text { express people's desire } \\
\text { for a better life }\end{array}$ \\
\hline
\end{tabular}

\subsection{Structural indicator}

Functional indicators are symbols that express meaning on the basis of functional Causality. The structure generally refers to the structural component, is used to constitute the main functional component of the furniture frame[6]. Hakka furniture refers to the wooden beam frame structure in Chinese traditional buildings, and the free-standing frame construction of furniture from the Song Dynasty. Among them, the structural components play an extremely important role. The components of Hakka furniture are both functional and aesthetic, such as the table's yoke, backrest, and support.etc, which have both decorative and supporting functions. structural components are usually not carved and decorated, not only diversified in shape, but also more scientific and standard in collocation. in addition, with the continuous development of the technological level, the decorative effect will naturally be even better, fully reflecting the natural beauty of natural materials and the refined and elegant form structure.

\subsection{Layout symbols of furniture}

The symbolism of furniture and ornaments. In addition, the hakkas' meeting hall Furniture is well-made, which is the most beautiful of all the furniture in the interior of hakka residential buildings, especially in the main hall, without the baxian table (old-fashioned square table for eight people), taishi chair ( an old-fashioned wooden armchair), tiaoan (a long narrow table) and other furniture (figure 1). In the main hall, there are usually Hall paintings hanging on the walls of the master, and the couplets are symmetrically arranged on both sides, and there is a case under the couplets. There are pen, cap, clock, vase and mirror on the case, meaning "life (Bell) flat (bottle) quiet (mirror)." The baxian table (oldfashioned square table for eight people and the taishi chair (an old-fashioned wooden armchair), which are close to the tiaoan (a long narrow table), respectively place tea tables and chairs under them. they are orderly and strict, reflecting the ethical and moral order of Confucianism. calligraphy and paintings and some couplets are hung on the walls on each side, adding a strong atmosphere of book rolling, quiet and solemn.

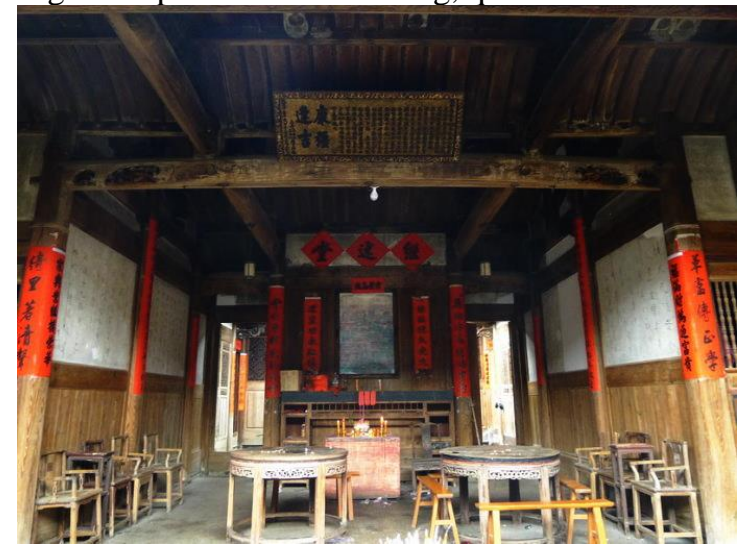

Figure1.Typical Hakka hall layout 


\section{Interpretation of the symbolic connotation of Hakka furniture}

The most representative of traditional Chinese furniture is Hakka furniture, which is not only a material existence, but also a symbolic existence[7].On the one hand, furniture has clear material form, that is," signifier "in semiotics; on the other hand, it contains content and meaning other than material form, that is,"signifier,"thus constituting an independent artistic symbol system.

\subsection{Carrier of traditional ideology and culture}

Traditional Chinese society is dominated by Confucian culture, therefore, Hakka furniture is influenced by traditional Confucianism which is centered on "benevolence" and "rites" and pursues a high degree of unity of function and form[8].The components of Hakka furniture are unified in decoration and function, such as chair legs, which have both supporting function and aesthetic decoration.Furniture should be balanced between decoration and function instead of paying too much attention to decoration.This reflects the Confucian "Doctrine of the Mean." Hakkas furniture generally adopts the design of middle symmetry, and the shape adopts the outline of straight line. The seat surface of the Hakka living room chair is high, and the backrest curve is ergonomically designed,and the person takes the posture of holding his chest and pulling his back when sitting, which is dignified and formal,and conforms to the Confucian ethical norms of serious sitting.

In addition, the space symbol under the Hakka chair is usually "square" to reflect the sense of "stable". In fact, as far as the furniture itself is concerned, the "furniture" as a whole is a symbol of coexistence of reality . Therefore, the practical functions, aesthetic functions, and philosophical ideas conveyed by the Hakka chair are expressed through the visual form of the furniture.

\subsection{Highly metaphorical shapes}

Furniture mainly conveys specific meaning implicitly with highly abstract symbols. First of all, the components of Chinese traditional furniture reflect the cultural psychology of conventions and customs in an abstract form. For example, the design of the circle chair, the upper part of the rounded arc represents the sky, and the lower part of the chair surface and leg adopts a square linear shape to represent the earth, which coincides with the ancient Chinese universe model. Another example is that some chairs are equipped with four legs on the lower side of the horizontal tent, the former low, high on both sides, the latter higher, known as "step by step to catch the tent", meaning "rise step by step". Secondly, the decorative patterns are also full of abstract meaning. for example, the "s"-shaped pattern extends outward at its four ends, implying continuous longevity and longevity; the original pattern of rolling grass is honeysuckle, because of its Cold-resistant characteristics, and does not die in winter, which is compared to the immortal soul and eternal life.

\subsection{Exquisitely structured dynamic form}

Hakka furniture based on Traditional furniture focuses on the overall shape. It absorbs the tenon and mortise structure in the traditional building. When connected, the various components mesh with each other to create a balanced beauty of height and length. This connection method of parts forms a flexible furniture model, which is supported by each other, and the strength and balance of the beauty produced by the whole body is far greater than the sum of the parts.In addition, Hakka traditional furniture reflects the philosophy of life through structure details. "waist-binding" is a waist line that makes a circle under the face edge of the furniture and converges inwards and is less in length than the face edge and the tooth strip. like adding a waist body to the furniture, the line treatment is flexible and rhythmic, and contains and changes.

\section{Conclusion}

In summary, Hakka furniture has always been rooted in traditional Chinese culture, conveying the aesthetic connotation of imagination in addition to structure and form. As a symbol carrying cultural information, Hakka furniture belongs to a symbol system of a specific culture, which requires us to follow the specific laws of symbol propagation when dealing with the protection and research of Hakka traditional furniture symbols, and deal with all levels of the Hakka furniture symbol system. To avoid misalignment and fragmentation. Only in this way can Hakka traditional furniture be better protected and developed.

\section{References:}

1. Wan Luzhu. Introduction to Hakka Studies [M]. Jiangxi University Press, 1995.

2. Tang Kaijun. Furniture decoration patterns and styles [M]. China Architecture \& Building Press, 2004

3. Hu Desheng. Traditional furniture and traditional concepts [M] .China Light Industry Press, 1999

4. He Yan Li .Study on the Symbol Theory of Traditional Chinese Furniture's Ornament [D]. Beijing Forestry University, 2006 p121

5. Wu Shan. Research on the Emotionalization of Furniture Form Elements [D]. Beijing Forestry University, 2009.

6. Wang Shixiang. Appreciation of Ming-style furniture [M]. Cultural Relics Publishing House, 2003.

7. Chen W,Shulan YU,Boming XU. Study on the Furniture Design Based on Product Semantics[J]. Art \& Design ,2013.

8. Yuan Li. Classics of Chinese Folklore.Social Folklore Volume [M]. Publication of Social Science Literature, 2002. 